\title{
Polyarthritis and pitting oedema
}

\author{
Jean Dudler, Jean-Charles Gerster, Alexander So
}

\section{Service de}

Rhumatologie,

Médecine Physique et

Rééducation, Centre

Hospitalier

CHUV - 1011

Lausanne, Switzerland

Correspondence to:

Dr J Dudler.

Accepted for publication
Universitaire Vaudois,

2 December 1998

\section{Case history}

CASE 1

A 74 year old white man presented with an abrupt onset of metacarpophalangeal (MCP) and interphalangeal (IP) joint pains associated with swelling of both hands. He had two hours of morning stiffness but no other joint complaints or history of constitutional symptoms. Past medical history was unremarkable except for diabetes mellitus type 2 treated with oral antidiabetic drugs.

Examination showed gross pitting oedema of the dorsum of both hands with swollen and tender MCPs, severe tenosynovitis of the flexor
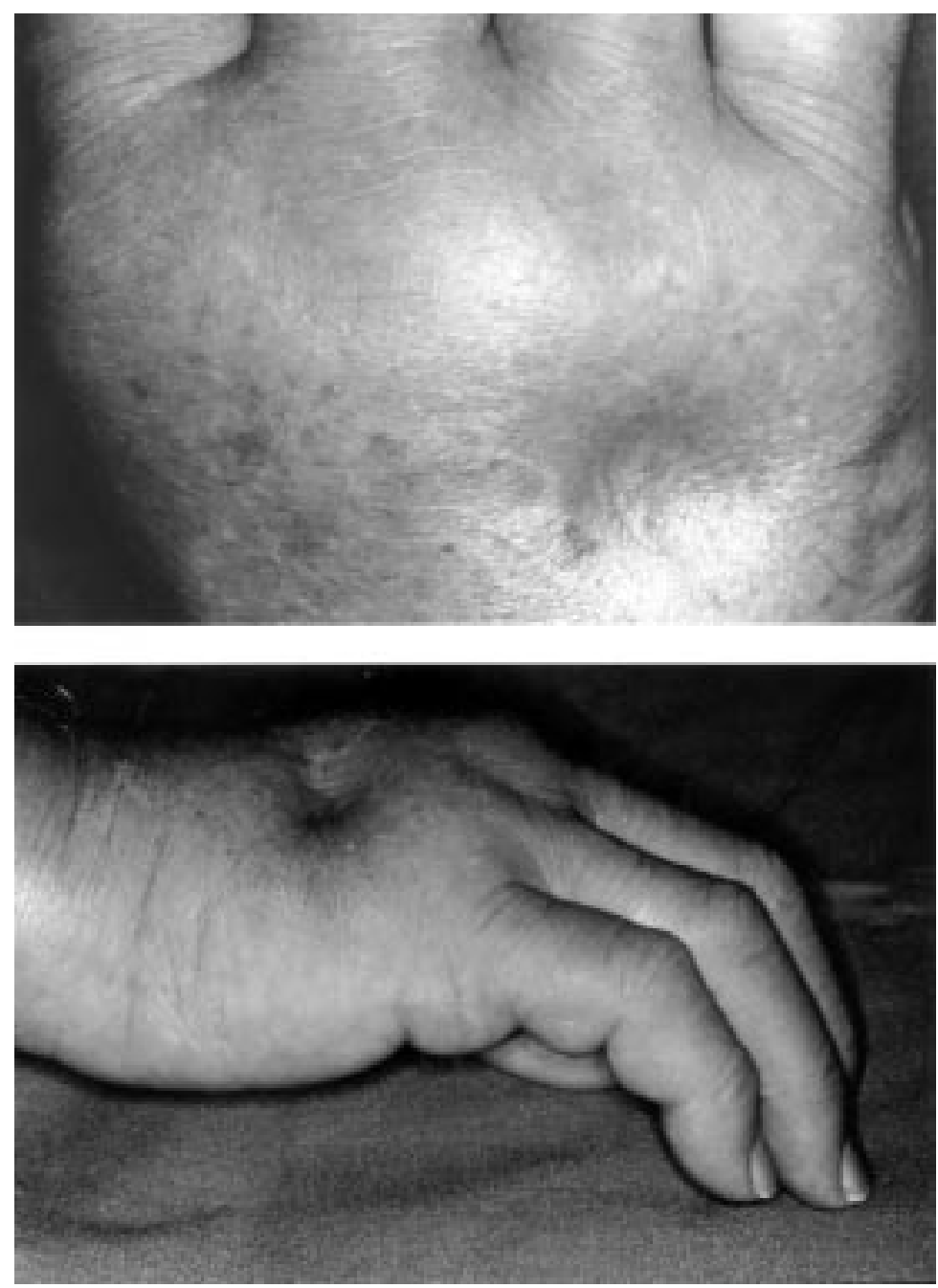

Figure 1 Severe pitting oedema of the dorsum of the hand. tendons, and swollen and limited wrist movements. Both knees had painless small effusions. Other joints showed no signs of inflammation and no nodules were palpated.

The erythrocyte sedimentation rate was increased at $55 \mathrm{~mm}$ in the first hour. Except for a mild inflammatory anaemia and hyperglycaemia between 8 to $10 \mathrm{mmol} / \mathrm{l}$, the full blood count, renal, liver and thyroid function tests were within normal limits. Electrophoresis demonstrated an acute and subacute inflammatory pattern without monoclonal peak and rheumatoid factor and ANA were negative. Four millilitres of clear synovial fluid were aspirated from the left knee. Cell count was $198 / \mathrm{mm}^{3}$ with no crystals.

The patient was treated with prednisone with a rapid clinical response. Maximal dose was $20 \mathrm{mg}$ per day, slowly tapered over four months to zero. No flare up was observed and after two years the patient was still asymptomatic and his sedimentation rate normal.

CASE 2

A 86 year old white man presented with a three week history of severe swelling of the right hand associated with pain and morning stiffness. Except for slight paresthesia in the hand, he had no other complaint. Past medical history was unremarkable.

Examination demonstrated severe pitting oedema of the dorsum of the right hand with swollen and tender MCPs (fig 1). The wrist was also swollen and limited with discrete signs of a carpal tunnel syndrome. The left wrist and one MCP joint were painful to palpation.

The erythrocyte sedimentation rate was 24 $\mathrm{mm}$ in the first hour and $\mathrm{C}$ reactive protein was $27 \mathrm{mg} / \mathrm{ml}$. Rheumatoid factor was negative. Arthrocentesis of the right wrist showed 750 leucocytes per $\mathrm{mm}^{3}$ with no crystals.

The patient was treated with $15 \mathrm{mg}$ of prednisone per day. Clinical response was rapid and the corticosteroids were tapered over the next 10 months without a flare up. Non-specific chronic synovitis was demonstrated on synovial biopsy at carpal tunnel release three months after the onset of the disease

CASE 3

A 78 year old white man suddenly developed pain and severe oedema of both hands. $\mathrm{He}$ also complained of shoulders, hips and knees pain with morning stiffness lasting 45 minutes. Diabetes mellitus and peripheral vascular disease 
were noted on past medical history, but no previous osteoarticular complaints.

On examination, diffuse oedema of both hands was present and the wrists were painful and very limited in mobility. Active mobilisation of the shoulder was also painful and limited. Effusions were present in both knees and no nodules were palpated.

The erythrocyte sedimentation rate was increased at $64 \mathrm{~mm}$ in the first hour and C reactive protein at $88 \mathrm{mg} / \mathrm{ml}$. Except for a discrete inflammatory anaemia $(114 \mathrm{~g} / \mathrm{l})$ and hyperglycaemia (between 9 and $12 \mathrm{mmol} / \mathrm{l}$ ), renal and thyroid function tests were normal. There was a moderate increase in alkaline phosphatase at $181 \mathrm{U} / 1$ (normal 36-108) associated with increased $\gamma$-glutamyltransferase $(72$ U/1, normal 11-62). Rheumatoid factor was negative and ANA slightly positive, speckled at $1 / 320$. Ten millilitres of clear synovial fluid were aspirated from the right knee. Cell count was $6800 / \mathrm{mm}^{3}$ and no crystals were demonstrated. Radiography demonstrated degenerative changes in IPD joints, but no erosion or calcification.

Prednisone $15 \mathrm{mg}$ daily was introduced with complete remission of pain and oedema.

Eight months later, the patient was rehospitalised for severe inflammatory lumbar pain. There was no residual complaints at the level of the hands or the shoulders then, but the patient had lost $5 \mathrm{~kg}$. Alkaline phosphatase was now highly increased at $2740 \mathrm{U} / 1$ with no change in $\gamma$-glutamyltransferase activities $(70 \mathrm{U} / 1)$. Bone scintigraph demonstrated multiple metastases in the vertebrae, pelvis, sacrum, clavicles, cranium and femurs from a biopsy confirmed prostatic adenocarcinoma. The patient died a few days later from pneumonia.

\section{Discussion}

THE RS3PE SYNDROME

The association of pitting oedema and arthritis of the hands is fairly rare and specific. It is very suggestive of a subset of the seronegative polyarthritides of the elderly, the RS3PE syndrome or "remitting seronegative symmetrical synovitis with pitting edema", as initially described by McCarty in $1985 .{ }^{1} \mathrm{He}$ isolated, from the heterogeneous group of elderly patients with polyarthritis, a subgroup of 10 patients all fulfilling the ARA (American Rheumatism Association) criteria for rheumatoid arthritis but who presented a distinctive clinical picture and evolution. The principal characteristics reported by McCarty in this seminal paper were confirmed in a latter paper of 13 additional cases ${ }^{2}$ and in numerous reports in the literature. ${ }^{3-7}$ Typically, as in our cases, patients are elderly white people (average $>70$, range 45 to 92 ) with a male predominance of about 3:1. Onset is rapid, in less than a month, often even explosive with patients able to pinpoint it to within a few hours. They note the simultaneous apparition of pain and symmetrical pitting oedema of the back of the hands. Pain involves the wrist, the MCPs and IPs as well as the flexor tendon sheaths of the fingers. Shoulder girdle pain is also frequently reported, contrasting with the rarity of symptoms from the pelvic girdle. Fever and asthenia are also occasionally present.

The clinical picture is characterised by a florid pitting oedema of the dorsum of the hands, which may also be present in the feet. There is always an important limitation of the wrists and, very often, small effusions of the knees are reported. Magnetic resonance imaging studies have demonstrated severe extensor tenosynovitis believed to be the principal lesion responsible for the oedema. ${ }^{8}$ In contrast, lymphoscintigraphy studies showed no reduction of axillary lymphnode radioactivity, indicating normal lymphatic function.

Laboratory tests typically demonstrate an inflammatory state with increased sedimentation rate and $\mathrm{C}$ reactive protein, discrete inflammatory anaemia and hypoalbuminaemia. Rheumatoid factor is negative. In cases where synovial fluid analyses were carried out, leucocyte counts were usually lower than in rheumatoid arthritis and in our cases, the values 198,750 , and $6800 / \mathrm{mm}^{3}$ are typical.

Radiography of the hands and wrists show soft tissue oedema and generalised osteopenia. Bone erosions are absent.

Crucial for the definition of the syndrome, functional prognosis is excellent. Duration of treatment is usually less than a year and, in almost all cases reported, complete and sustained remission was obtained even after withdrawal of medication. Treatments used vary widely: from non-steroidal antiinflammatory drugs (NSAIDs) to salicylates, antimalarials, gold salts, and corticosteroids. Low dose prednisone (10 to $15 \mathrm{mg} /$ day) was found to be effective with a rapid and spectacular effect, while response rate was variable and slower with other treatments. Again, long term functional prognosis is excellent, except for a small persisting limitation of the wrists or the fingers.

The aetiology of the syndrome is still unknown. The clustering of patients from rural areas and the seasonal variation, with peaks in summer and autumn, initially suggested to McCarty an infectious or para-infectious origin. ${ }^{1}$ Nevertheless, serological studies for Borrelia burgdorferi remained negative and epidemiological case-control studies did not show any special exposition to an infectious or toxic agent. ${ }^{2}$ A search for a retroviral aetiology has also been negative. ${ }^{9}$ Finally, McCarty reported an increased prevalence of HLA B7, found in 15 of 23 patients (59\%) compared with $24 \%$ in a control white population (relative risk 4.4). ${ }^{2}$ Even if this finding has not been confirmed by other groups, this tends to distinguish RS3PE as a specific entity apart from rheumatoid arthritis and other seronegative polyarthritides of the elderly.

As always the case in medicine, RS3PE can present atypically. Asymmetrical cases, like case number 2 , have been reported. Two were in patients with neurological disease (longstanding hemiparesis), ${ }^{10}$ similar to that reported in rheumatoid arthritis, and one without neurological involvement. ${ }^{11}$ Three 
Table 1 Differential diagnosis of oedema and arthritis of the hands

\begin{tabular}{|c|c|c|}
\hline Diagnosis & Clinical features & Investigations \\
\hline RS3PE syndrome & $\begin{array}{l}\text { Elderly male. Exquisite response to low dose corticosteroids. Long } \\
\text { term remission after withdrawal }\end{array}$ & $\begin{array}{l}\text { Negative } \mathrm{RF} \text { and ANA. No erosion on } \\
\text { radiography }\end{array}$ \\
\hline $\begin{array}{l}\text { Mixed connective tissue disease } \\
\text { (Sharp syndrome) }\end{array}$ & Young female Raynaud phenomena & High titre speckled ANA (U1-RNP specificity) \\
\hline CPPD disease (chondrocalcinosis) & $\begin{array}{l}\text { Elderly patient, female predominance. Often asymmetric, absence of } \\
\text { constitutional symptoms. Good clinical response to NSAIDs }\end{array}$ & $\begin{array}{l}\text { Chondrocalcinosis on hands, knee and pelvic } \\
\text { radiography. Crystal demonstration by synovial } \\
\text { fluid analysis with polarised light }\end{array}$ \\
\hline $\begin{array}{l}\text { Reflex sympathic dystrophy } \\
\text { (Sudeck's disease, algodystrophy) }\end{array}$ & $\begin{array}{l}\text { Exquisitely painful oedema, vasomotor and skin alterations. Absence of } \\
\text { true arthritis, presence of predisposing factors }\end{array}$ & $\begin{array}{l}\text { Absence of systemic inflammation. Radiological } \\
\text { exams (standard radiographs, bone scintigram and } \\
\text { RMI) }\end{array}$ \\
\hline Amyloid arthropathy & $\begin{array}{l}\text { Rare disease, firm and non-inflammatory pseudo-oedema Frequent } \\
\text { nodules and carpal tunnel syndrome. Slow and insidious onset and no } \\
\text { morning stiffness. Polyvisceral involvement }\end{array}$ & $\begin{array}{l}\text { Proteinuria, monoclonal gammapathy or light } \\
\text { chain in urine (AL type). Demonstration on free } \\
\text { amyloid debris in synovial fluid and/or specific } \\
\text { birefregence with Congo Red staining on biopsies }\end{array}$ \\
\hline $\begin{array}{l}\text { Reiter's or psoriatic } \\
\text { spondylarthropathy }\end{array}$ & $\begin{array}{l}\text { Cutaneous, axial, ocular or urogenital signs and symptoms. Mostly } \\
\text { asymmetrical, sausage fingers Occasionally firm and non-pitting } \\
\text { lymphoedema }\end{array}$ & HLA-B27 positive. Sacroiliitis on radiography \\
\hline Late onset spondylarthropathy & $\begin{array}{l}\text { Asymmetrical pitting oedema of lower limbs with oligoarthritis. Middle } \\
\text { aged men. Severe constitutional symptoms. Poor response to } \\
\text { corticosteroids }\end{array}$ & HLA-B27 positive. No axial disease \\
\hline Rheumatoid arthritis & $\begin{array}{l}\text { Female predominance, symmetrical synovitis of MCPs and IPs. Good } \\
\text { but not dramatic response to corticosteroids }\end{array}$ & $\mathrm{RF}$, erosions on radiography \\
\hline Polymyalgia rheumatica & $\begin{array}{l}\text { Elderly patient (female predominance } 1.5-2: 1 \text { ). Rare true peripheral } \\
\text { synovitis, usually mild. Dramatic response to corticosteroids but long } \\
\text { duration of treatment and frequent flares }\end{array}$ & Temporal artery biopsy \\
\hline
\end{tabular}

cases, typical but for their young age (30 years of age in average) have also been reported.

\section{RS3E AND ASSOCIATED DISEASES}

RS3PE syndrome has, by definition, a good prognosis. Nevertheless, there have been reports of apparently classic RS3PE syndromes that were complicated by connective tissue diseases such as polyarteritis nodosa ${ }^{12}$ or other vasculitides. ${ }^{13}$ Pitting oedema typical of RS3PE was reported in lupus, ${ }^{14}$ ankylosing spondylitis, ${ }^{15}$ and temporal arteritis. ${ }^{16}$ A prospective study looked at pitting oedema of the hands as a prognostic factor in various subsets of late onset rheumatoid arthritis (RS3PE, seropositive cases, cases with erosions or who relapsed after corticosteroids withdrawal). ${ }^{17}$ Interestingly, pitting oedema was found to be an independent factor (from the diagnosis of RS3PE) identifying, at onset, a favourable outcome in elderly patients with polyarthritis. ${ }^{17}$

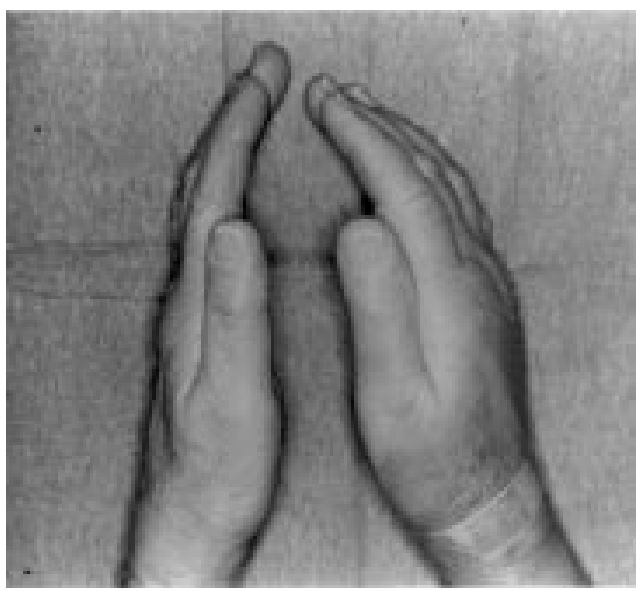

Figure 2 Abrupt onset of oedema and pain of the left hand in an 80 year old women secondary to a chondrocalcinosis crisis confirmed by arthrocentesis and radiography.
RS3PE syndrome has also recently emerged as a potential paraneoplastic syndrome. Cases of gastric carcinoma, ${ }^{18}$ endometrial carcinoma, ${ }^{19}$ and pancreatic carcinoma ${ }^{20}$ have been reported in association with RS3PE. In all cases, complete remission was observed after resection of the tumour, indicating a true paraneoplastic syndrome. Our case number 3 is representative of such patient. A confident diagnosis of a paraneoplastic syndrome could not be reached as the tumour was too advanced for specific treatment. In this older population, chance concurrence of both diseases could not be excluded, but such examples emphasise the need for a thorough examination in elderly patients with RS3PE syndrome, and heightened suspicion of potential underlying malignant diseases, especially if the response to corticosteroids is mitigated.

Finally, two of our patients had diabetes mellitus. No specific association of RS3PE with diabetes has been reported and this represents most probably the coincidence with a common comorbidity in the elderly population.

OEDEMA AND ARTHRITIS OF THE HANDS:

DIFFERENTIAL DIAGNOSIS

The association of arthritis and oedema of the hands is fairly unusual and should lead us to consider certain diagnoses when confronted by such cases. RS3PE is not the sole diagnosis and a list of other differential diagnoses, with some helpful clinical features and investigations to establish the diagnostic, are discussed and summarised in table 1 .

Mixed connective tissue disease (Sharp syndrome) Oedema of the hands, particularly the fingers with a sausage-like appearance, associated to a thickened, tightened and inelastic skin was present in $88 \%$ of the initial cases reported by Sharp ${ }^{21}$ and is still a main criteria in all the diagnosis criteria sets in use. ${ }^{22}$ Typically, and unlike RS3PE, patients will be young (average age 36$)$, female $(84 \%)$, and suffering from Raynaud phenomena (84\%). They may also 
demonstrate ulcerations or erythematous lesions suggestive of dermatopolymyositis. Finally, presence of high titre speckled ANA with U1-RNP specificity, the hallmark of this syndrome, will allow this diagnosis to be made.

\section{CPPD (chondrocalcinosis)}

In the elderly, CPPD can also be associated with oedema of the dorsum of the hands and acute or subacute inflammatory state (fig 2). Asymmetric oedema, female sex, and absence or little constitutional symptoms (although C reactive protein and sedimentation rate can be increased) all favour this diagnosis. Radiography and analysis of the synovial fluid under polarised light should establish the correct diagnosis. A rapid and favourable response to NSAIDs alone is also helpful.

Reflex sympathetic dystrophy (Sudeck's disease, algodystrophy)

Oedema of the hands can be the presentation of reflex sympathetic dystrophy that may be bilateral. Exquisite pain aggravated by active and passive mobilisation, vasomotor and skin alterations, absence of true arthritis, presence of predisposing factor such as myocardial infarction, stroke or use of barbiturates, and the absence of systemic inflammation will generally lead to the correct diagnosis. ${ }^{23}$ Radiography, bone scintigraphy, and magnetic resonance imaging can be useful but are not specific for diagnostic.

Amyloid arthropathy

Puffy hands have been described in amyloid arthropathy. It is rare, almost exclusively from the AL type and generally associated with light chain multiple myeloma. ${ }^{24}{ }^{25}$ The involvement is better described as a pseudo-oedema as it is not or only slightly inflammatory and abnormally firm on palpation. The onset is typically insidious and morning stiffness rare and brief. The evolution is progressive and extraarticular symptoms are related to the polyvisceral involvement, which will appear at onset or during evolution (particularly kidney involvement with proteinuria). Immunofixation and demonstration of the specific birefringence with Congo Red on a biopsy or synovial fluid (free amyloid debris) will lead to the correct diagnosis.

Psoriatic arthritis and Reiter's syndrome

Diagnosis is not difficult but one should be aware that spondyloarthropathies, especially psoriatic arthritis or Reiter's syndrome, can present with oedema of the hands. Involvement is often asymmetrical, resulting from severe tenosynovitis of the flexor tendons, with the typical sausage fingers. Lymphoedema, resulting from impaired lymphatic function (confirmed by isotope lymphography), has also been reported in psoriatic spondylarthropathy. ${ }^{26-28}$ Unlike the oedema of RS3PE, the oedema is firm, non-pitting and usually affects the entire forearm or arm. Interestingly, these cases seem to benefit more from NSAIDs than corticosteroids.
Key points

- RS3PE is a definite subset of the seronegative symmetrical polyarthritis of the aged characterised by dramatic pitting oedema of the hands, male predominance, old age, exquisite response to corticosteroids, and long term remission after withdrawal.

- RS3PE may be part of a paraneoplastic syndrome and heightened suspicion for underlying malignancy is important, especially if the response to corticosteroids is poor.

- The differential diagnosis of arthritis that presents with prominent peripheral oedema needs to be considered before making a diagnosis.

Late onset peripheral spondylarthropathy

Pitting oedema is a feature of late onset peripheral spondylarthropathy as described by Dubost et $a l,{ }^{29}$ but unlike RS3PE, it affects mainly the lower limb (involvement of the hands is rare) and is often asymmetrical. ${ }^{29} 30$ Patients are middle aged men (slightly younger than in RS3PE with an average around 60) appearing severely ill with prominent constitutional symptoms. Axial involvement is usually absent but mild oligoarthritis of the lower limbs is typical. Unlike RS3PE, response to NSAIDs and corticosteroids is poor and the disease remains active generally for several years. Finally, in all the cases described, HLA-B27 was positive. ${ }^{31}$

\section{Rheumatoid arthritis}

Rheumatoid arthritis in the elderly population (reviewed by van Schaardenburg and Breedveld $^{32}$ ) presents more frequently with abrupt and polymyalgia-like onset with limb girdle symptoms. Eleven to $48 \%$ are also rheumatoid factor negative. ${ }^{32}$ However, pitting oedema is not a specific feature of rheumatoid arthritis. Rarely, oedema of the hands have been observed during severe flare ups and hence attributed to changed capillary permeability secondary to the diffuse inflammatory process. ${ }^{33}$ Unilateral oedema resulting from a capsular rupture at the wrist, similar to the Baker cyst rupture in the knees, has also been reported..$^{33}$ Finally, a few rare cases of a firm, non-pitting lymphoedema, affecting the entire arm and attributed to lymphangitis secondary to the rheumatoid process, have been described..$^{27-38}$ Lymphoscintigraphy $^{35}$ as well as lymphography ${ }^{34}$ demonstrated changes in lymphatic drainage. Unlike the prompt response observed in $\mathrm{RS} 3 \mathrm{PE}$, these cases of rheumatoid lymphoedema do not respond well to second line treatment or corticosteroids..$^{27} 34$ Demonstration of erosions or positive rheumatoid factor exclude the diagnosis of RS3PE, while high leucocyte counts in synovial fluid favours the diagnosis of rheumatoid arthritis. Nevertheless, immediate differentiation with RS3PE could be impossible and only dramatic response to 
low dose corticosteroids and long term remission after withdrawal will allow definite diagnosis.

\section{Polymyalgia rheumatica}

Probably the toughest differential diagnosis of RS3PE, polymyalgia rheumatica has to be considered in an elderly patient who develops an acute inflammatory syndrome, morning stiffness, shoulder girdle pain, and hand oedema. Although pitting oedema of the hands is not a classic feature of polymyalgia rheumatica, the Mayo Clinic reported pitting oedema in 19 of 245 cases of polymyalgia rheumatica. ${ }^{39}$ Three additional cases were later reported by Caliani et al. ${ }^{40}$ McCarty maintained that he had personally never seen, in almost 40 years of practice, the dramatic oedema as found in RS3PE in polymyalgia. $^{41}$

Polymyalgia is more frequent in women, with a sex ratio between 1.5 to $2: 1$, depending on the cohort studied. ${ }^{42}{ }^{43}$ It involves the shoulder girdle in about $100 \%$ of the cases, but also very frequently the pelvic girdle (between 65 to $79 \%),{ }^{42-44}$ compared with RS3PE where it is much rarer. Also, true peripheral synovitis, usually mild, is found in only 5 to $15 \%$ of the cases. ${ }^{45-47}$ Although polymyalgia rheumatica responds dramatically to prednisone as RS3PE, flares are frequent and the duration of treatment much longer. ${ }^{48}$ Finally, HLA typing demonstrated increased prevalence of $\mathrm{B} 7$ for RS3PE but DR4 for polymyalgia, ${ }^{49-52}$ pointing toward similar but distinctive syndromes in this elderly population.

1 McCarty DJ, O'Duffy JD, Pearson L, Hunter JB. Remitting seronegative symmetrical synovitis with pitting edema. RS3PE syndrome. JAMA 1985;254:2763-7.

2 Russell EB, Hunter JB, Pearson L, McCarty DJ. Remitting, seronegative, symmetrical synovitis with pitting edema-13 additional cases. J Rheumatol 1990;17:633-9.

3 Stalder J, Gerster JC. La polyarthrite oedémateuse bénigne de la personne âgée (syndrome RS3PE). A propos de 11 cas personnels. Schweiz Med Wochenschr 1994;124:35761 .

4 Bridges AJ, Hickman PL. RS3PE syndrome and polymyalgia rheumatica: distinguishing features. J Rheumatol 1991; gia rheuma

5 Olive A, del Blanco J, Pons M, Vaquero M, Tena X. The clinical spectrum of remitting seronegative symmetrical synovitis with pitting edema. The Catalan Group for the Study of RS3PE. J Rheumatol 1997;24:333-6.

6 Chaouat D, Le Parc JM. The syndrome of seronegative symmetrical synovitis with pitting edema (RS3PE syndrome): a unique form of arthritis in the elderly? Report of 4 additional cases. J Rheumatol 1989;16:1211-13.

7 Schaeverbeke T, Fatout E, Marce S, Vernhes JP, Halle O, Antonie JF, et al. Remitting seronegative symmetrical synovitis with pitting oedema: disease or syndrome? Ann Rheum Dis 1995;54:681-4.

8 Olivieri I, Salvarani C, Cantini F. Remitting distal extremity swelling with pitting edema: a distinct syndrome or a clinical feature of different inflammatory rheumatic diseases? J Rheumatol 1997;24:249-52.

9 Russell EB, McCarty DJ, Schwab J, Hanel D, Komorowski R, Stransky G, et al. RS3PE syndrome: no evidence for retroviruses. J Rheumatol 1994;21:1105-6.

10 Pariser KM, Canoso JJ. Remitting, seronegative (A) symmetrical synovitis with pitting edema-two cases of RS3PE syndrome. J Rheumatol 1991;18:1260-2.

11 Olivieri I, Padula A, Favaro L, Oranges GS, Ferri S. RS3PE syndrome with unilateral involvement. J Rheumato 1994;21:372.

12 Billey T, Navaux F, Lassoued S. Remitting seronegative symmetrical synovitis with pitting edema (RS3PE) as the first manifestation of periarteritis nodosa. Report of a case. Rev Rhum Engl Ed 1995;62:53-4.

13 Ike RW, Blaivas M. Corticosteroid responsive puffy hands and occult vasculitic neuropathy: RS3PE plus? J Rheumatol $1993 ; 20: 205-6$.

14 Pittau E, Tinti A, Martini L, Bogliolo A, Perpignano G. Systemic lupus erythematosus with pitting oedema of the dis-
tal lower limbs. Br J Rheumatol 1998;37:104-5.
15 Koeger AC, Karmochkine M, Chaibi P. RS3PE syndrome Koeger AC, Karmochkine M, Chaibi P. RS3PE syndrome
associated with advanced ankylosing spondylitis. J Rheumatol 1995;22:375-6.

16 Marce S, Schaeverbeke T, Bannwarth B, Dehais J. Seronegative symmetrical polyarthritis with pitting oedema associated with antinuclear antibodies and a past history of giant cell arteritis. Br J Rheumatol 1994;33:1200-1.

17 Bhakta BB, Pease CT. Late-onset rheumatoid arthritis: is pitting oedema of the hands at onset a good prognostic indicator? Br J Rheumatol 1997;36:214-19.

18 Tada Y, Sato H, Yoshizawa S, Kimura H, Kitamura M, Kusaba T, et al. Remitting seronegative symmetrical synovitis with pitting edema associated with gastric carcinoma. I Rheumatol 1997;24:974-5.

19 Olivo D, Mattace R. Concurrence of benign edematous polysynovitis in the elderly (RS3PE syndrome) and endome-
trial adenocarcinoma. Scand J Rheumatol 1997;26:67-8.

20 Cantini F, Olivieri I, Salvarani C. More on remitting seronegative symmetrical synovitis with pitting edema as egative symmetrical synovitis with pitting edema

21 Sharp GC, Irvin WS, Tan EM, Gould RG, Holman HR. Mixed connective tissue disease-an apparently distinct rheumatic disease syndrome associated with a specific antibody to an extractable nuclear antigen (ENA). Am J Med 1972;52:148-59.

22 Amigues JM, Cantagrel A, Abbal M, Mazieres B. Comparative study of 4 diagnosis criteria sets for mixed connective tissue disease in patients with anti-RNP antibodies. Autoimmunity Group of the Hospitals of Toulouse. J Rheumatol 1996;23:2055-62.

23 Hérisson C, Claustre JLS. Les algodystrophies sympathiques réflexes. La Pratique Médicale 1985;38:7-29.

24 Roux S, Kahn MF, Fermand JP. Manifestations articulaires des gammapathies monoclonales. Ann Med Interne 1995; 146:268-73.

25 Cohen AS, Canoso JJ. Rheumatological Aspects of Amyloid Disease. Clin Rheum Dis 1975;1:149-61.

26 Salvarani C, Macchioni PL, Veneziani M, Rossi F, Lodi L, Baricchi R, et al. Upper limb lymphedema in psoriatic arthritis. J Rheumatol 1990;17:273-4.

27 Salvarani C. Upper limb lymphedema in inflammatory arthropathy. J Rheumatol 1995;22:370.

28 Mulherin DM, Fitzgerald O, Bresnihan B. Lymphedema of the upper limb in patients with psoriatic arthritis. Semin Arthritis Rheum 1993;22:350-6.

29 Dubost JJ, Sauvezie B. Late onset peripheral spondyloarthropathy. J Rheumatol 1989;16:1214-17.

30 Olivieri I, Oranges GS, Sconosciuto F, Padula A, Ruju GP, Pasero G. Late onset peripheral seronegative spondyloarthropathy: report of two additional cases. J Rheumatol 1993;20:390-3.

31 Javier RM, Sibilia J, Kuntz JL, Asch L. Spondylarthropathie à début tardif? RS3PE? Forme de chevauchement? Rev Rhum 1991;58:553.

32 van Schaardenburg D, Breedveld FC. Elderly-onset rheumatoid arthritis. Semin Arthritis Rheum 1994;23:367-78.

33 Dryll A, Debeyre N. Les oedèmes des polyarthrites rhumatoïdes. In: DeSèze S, Ryckewaert A, Kahn MF, Peltier AP, eds. L'Actualité Rhumatologique 1972. Paris: Expansion Scientifique Française, 1973:23-38

34 Grillet B, Dequeker J. Rheumatoid lymphedema. J Rheumatol 1987;14:1095-7.

35 Kiely PD, Joseph AE, Mortimer PS, Bourke BE. Upper limb ymphedema associated with polyarthritis of rheumatoid type . J Rheumatol 1994;21:1043-5.

36 de Silva RT, Grennan DM, Palmer DG. Lymphatic obstruction in rheumatoid arthritis: a cause for upper limb oedema. Ann Rheum Dis 1980;39:260-5.

37 Kyle VM, De Silva M, Hurst G. Rheumatoid lymphoedema. Clin Rheumatol 1982;1:126-7.

38 Kalliomaki JL, Vastamaki M. Chronic diffuse oedema of the rheumatoid hand: a sign of local lymphatic involvement. Ann Rheum Dis 1968;27:167-9.

39 Salvarani C, Gabriel S, Hunder GG. Distal extremity swellng with pitting edema in polymyalgia rheumatica. Report on nineteen cases. Arthritis Rheum 1996;39:73-80.

40 Caliani L, Paira S. Distal extremity swelling with pitting edema in polymyalgia rheumatica. Arthritis Rheum 1997; 40:1551-2.

41 McCarty DJ. Comparison of polymyalgia rheumatica and remitting seronegative symmetrical synovitis with pitting edema syndrome: comment on the article by Salvarani et al. Arthritis Rheum 1996;39:1931-2.

42 Chuang TY, Hunder GG, Ilstrup DM, Kurland LT. Polymyalgia rheumatica: a 10 -year epidemiologic and clinicalymyalgia rtudy. Ann Intern Med 1982;97:672-80.

43 Myklebust G, Gran JT. A prospective study of 287 patients with polymyalgia rheumatica and temporal arteritis: clinical and laboratory manifestations at onset of disease and at the time of diagnosis. Br J Rheumatol 1996;35:1161-8.

44 Salvarani C, Gabriel SE, O'Fallon WM, Hunder GG. Epidemiology of polymyalgia rheumatica in Olmsted County, Minnesota, 1970-1991. Arthritis Rheum 1995;38:369-73.

45 Chaouat D. Peripheral joint involvement in polymyalgia rheumatica. Rev Rhum Engl Ed 1997;64:184-8.

46 Devauchelle V, Saraux A, Youinou P, Le Goff P. Prevalence of synovitis in patients with polymyalgia rheumatica and/or giant cell arteritis. Rev Rhum Engl Ed 1997;64:594-5.

47 Kyle V, Tudor J, Wraight EP, Gresham GA, Hazleman BL. Rarity of synovitis in polymyalgia rheumatica. Ann Rheum Dis 1990;49:155-7.

48 Ayoub WT, Franklin CM, Torretti D. Polymyalgia rheumatica. Duration of therapy and long-term outcome. Am J Med 1985;79:309-15. 
49 Cid MC, Ercilla G, Vilaseca J, Sanmarti R, Villalta J, Ingelmo $\mathrm{M}$, et al. Polymyalgia rheumatica: a syndrome associated with $M$, et al. Polymyalgia rheumatica: a syndrome associated

50 al-Jarallah KF, Buchanan WW, Sastry A, Singal DP. Immunogenetics of polymyalgia rheumatica. Clin Exp Rheumatol 1993;11:529-31.
51 Uddhammar A, Sojka BN, Rantapaa-Dahlqvist S. HLA antigens in polymyalgia rheumatica in northern Sweden. antigens in polymyalgia rheumati
Clin Rheumatol 1996;15:486-90.

52 Sakkas LI, Loqueman N, Panayi GS, Myles AB, Welsh KI. Immunogenetics of polymyalgia rheumatica. Br J Rheumatol 1990;29:331-4.

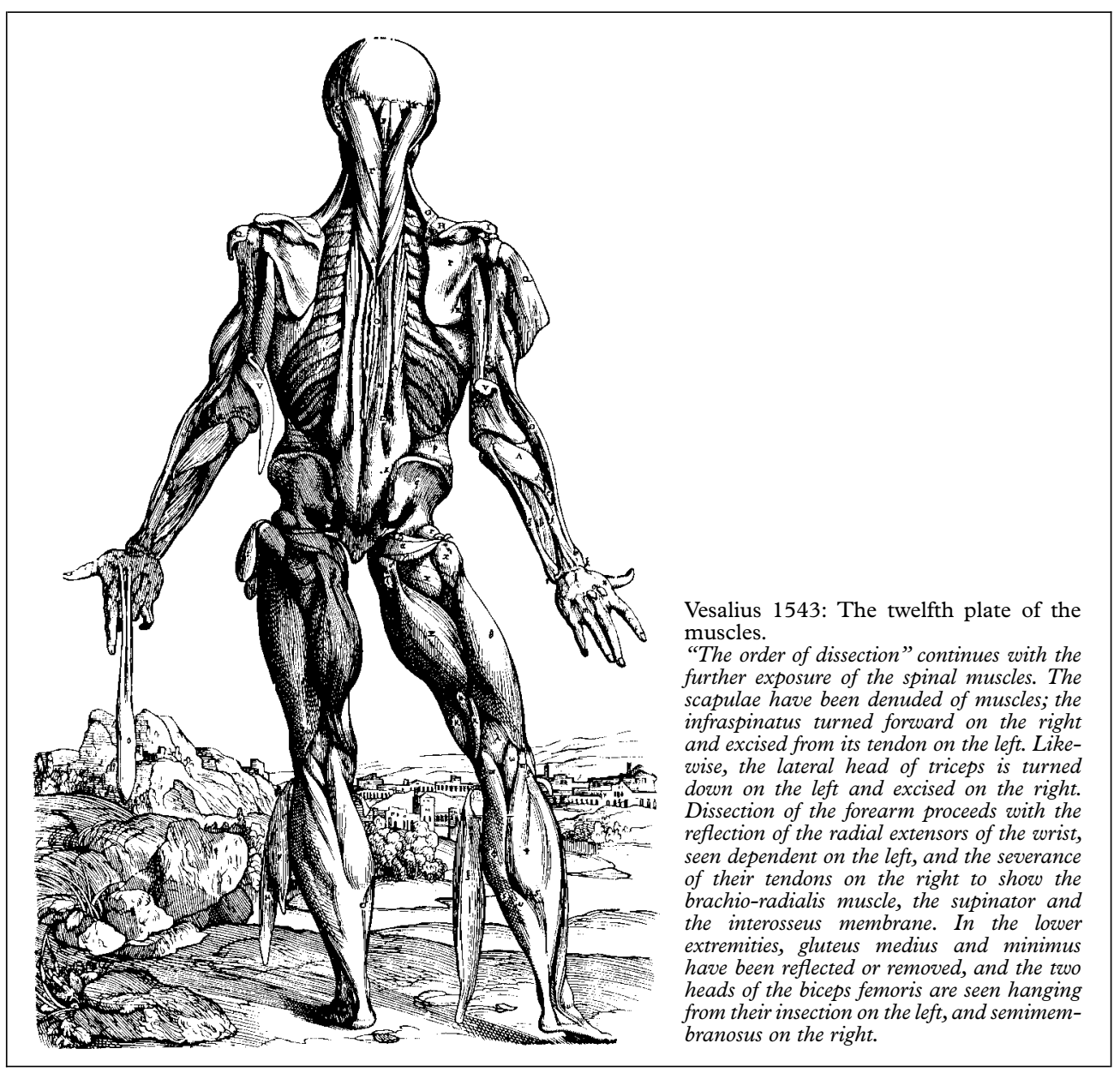

Vesalius 1543: The twelfth plate of the

"The order of dissection" continues with the further exposure of the spinal muscles. The capulae have been denuded of muscles; the reflection of the radial extensors of the wrist, seen dependent on the left, and the severance their tendons on the right to show the ch-radialis muscle, the supinator and interosseus membrane. In the lower 